\title{
ESTUDO DAS MANIFESTAÇÕES PATOLÓGICAS EM EDIFÍCIOS DE ESTRUTURA METÁLICA DA UNIVERSIDADE FEDERAL DE VIÇOSA
}

\author{
MENDES, BEATRYZ CARDOSO \\ Doutoranda em Engenharia Civil \\ Universidade Federal de Viçosa \\ Minas Gerais; Brasil \\ beacm03@gmail.com
}

\section{SANTOS, RODRIGO FELIPE}

Doutorando em Engenharia da Construção

Universidade Federal de Viçosa

Minas Gerais; Brasil

rodrigo.felipe@ufv.br

\author{
SILVA, REGINALDO CARNEIRO DA \\ Professor Associado \\ Universidade Federal de Viçosa \\ Minas Gerais; Brasil \\ recsilva@ufv.br
}

\section{RESUMO}

O presente trabalho teve como objetivo a avaliação de manifestações patológicas presentes em edifícios institucionais de estrutura metálica, situados na Universidade Federal de Viçosa (UFV - Minas Gerais). Ao todo, cinco edificações, de múltiplos pavimentos, foram vistoriadas. A metodologia consistiu, primeiramente, em um levantamento de campo com exame visual e registro fotográfico dos problemas, com a obtenção dos aspectos gerais de cada manifestação. Posteriormente, realizou-se a análise dos resultados, e indicação das possíveis causas e ações para a correção das anomalias observadas. As principais manifestações patológicas detectadas estão associadas, de modo geral, às corrosões e às ligações entre a alvenaria e as peças estruturais. Além da correção dos problemas, propôs-se também algumas medidas que podem ser adotadas para a prevenção de patologias nesse âmbito. Dessa forma, o trabalho contribuiu para o aumento de informações sobre manifestações patológicas em estruturas metálicas, e consequente melhoria da qualidade desse sistema estrutural, sobretudo no contexto de edificações institucionais. Palavras-chave: manifestações patológicas, edificação, estrutura metálica, qualidade.

\section{ABSTRACT}

The present work aimed at the evaluation of pathological manifestations in institutional buildings with steel structure, located at Federal University of Viçosa (UFV - Minas Gerais). In all, five buildings with multiple floors were inspected. The methodology consisted, firstly, of a field survey with visual examination and photographic register of the problems, obtaining the general aspects of each manifestation. Subsequently, the results were analyzed and possible causes and actions to correct the anomalies were indicated. The main pathological manifestations detected are generally associated with corrosion and the connections between masonry and structural parts. In addition to correcting the problems, some procedures that can be adopted to prevent pathologies in this building system were also proposed. Thus, the work contributed to the increase of information on pathological manifestations in steel structures, and consequent improvement of the their quality, especially in the context of institutional constructions.

Keywords: pathological manifestations, building, steel structures, quality.

\section{INTRODUÇÃO}

As estruturas metálicas, ou estruturas em aço, constituem um sistema construtivo no qual os elementos estruturais são constituídos do material aço. No Brasil, a utilização deste sistema tem se intensificado nas últimas décadas devido a vantagens como a possibilidade de peças estruturais com menores seções transversais - resultando em um menor peso próprio da estrutura; e a industrialização inerente aos processos de montagem das estruturas e produção do aço e de perfis estruturais (CORTEZ et al., 2017).

De fato, a industrialização permite que o processo de produção seja racionalizado, incrementando a velocidade de execução e facilitando a implementação de outros componentes pré-fabricados na estrutura. Há ainda uma maior precisão na execução, eliminando ou reduzindo efeitos negativos como desníveis e desaprumos e a perda de material no canteiro de obras. Além disso, o material aço, também produzido em meio industrial, apresenta maior homogeneidade 
em relação ao concreto armado, de modo que o comportamento da estrutura é mais próximo do considerado a nível de projeto (CASTRO, 1999).

No entanto, para que uma edificação em estrutura metálica apresente todas essas vantagens, algumas premissas devem ser observadas: um projeto estrutural em aço deve ser adequadamente compatibilizado com os demais projetos da edificação, pois o fato das peças estruturais serem pré-fabricadas inviabiliza a alteração do projeto in loco; as equipes envolvidas nas etapas de concepção e execução devem contar com mão-de-obra qualificada, para que todos os procedimentos sejam realizados de maneira correta; utilização de materiais com boa qualidade; entre outras (CASTRO, 1999). Se estes requisitos não forem atendidos, estas estruturas se tornam mais susceptíveis à ocorrência de manifestações patológicas, das mais diversas naturezas.

Segundo Souza e Ripper (1998), as manifestações patológicas de uma estrutura podem ocorrer devido a agentes internos e externos, e cada material reage de forma particular a estes agentes. $\mathrm{O}$ estudo da patologia estrutural envolve uma análise detalhada dos problemas, descrevendo as causas, formas e mecanismos de ocorrência e medidas de correção (prognóstico) e manutenção (MARSIA; SARTORI, 2011).

Assim como nos demais sistemas construtivos, as edificações em estrutura metálica devem ser funcionais, seguras e duráveis. Estes aspectos são comprometidos diante do surgimento de manifestações patológicas causadas, na maioria das vezes, por falhas de concepção, projeto, execução, manutenção e utilização da estrutura (SANTOS; FIORITI; TSUTSUMOTO, 2016; SANTOS; TSUTSUMOTO; FIORITI, 2014).

As anomalias mais recorrentes são a corrosão do aço, deformações plásticas devido a carregamentos excessivos, fissuração e falta de estanqueidade nas ligações alvenaria/estrutura. As causas podem ter origens distintas, sendo essas as mais comuns: erros de cálculo e detalhamento; má execução dos detalhamentos previstos em projeto; uso de aços com resistências diferentes das especificadas em projeto; erros de montagem; falha no processo de pintura; falta de um programa de manutenção preventiva/corretiva; má utilização da edificação; e agentes externos ambientais (SACCHI; SOUZA, 2016). Mesmo sendo um assunto relevante para a engenharia civil, o estudo da patologia de edifícios em estrutura metálica ainda é limitado, carecendo de mais informações e estudos de caso.

Diante deste contexto, o objetivo do presente trabalho foi a detecção e análise de manifestações patológicas em edificações de estrutura metálica situadas na Universidade Federal de Viçosa - MG, campus Viçosa. Por meio de inspeção visual, foram apresentados os aspectos gerais das anomalias, possíveis causas e medidas de correção destes problemas. Além disso, foram propostas algumas ações gerais que podem promover o aumento da qualidade em estruturas metálicas. Dessa forma, tem-se um estudo que pode contribuir com informações úteis sobre as manifestações patológicas em estruturas de aço, sobretudo no âmbito de obras institucionais.

\section{METODOLOGIA}

A metodologia utilizada na presente pesquisa é descrita, brevemente, no fluxograma da Figura 1.

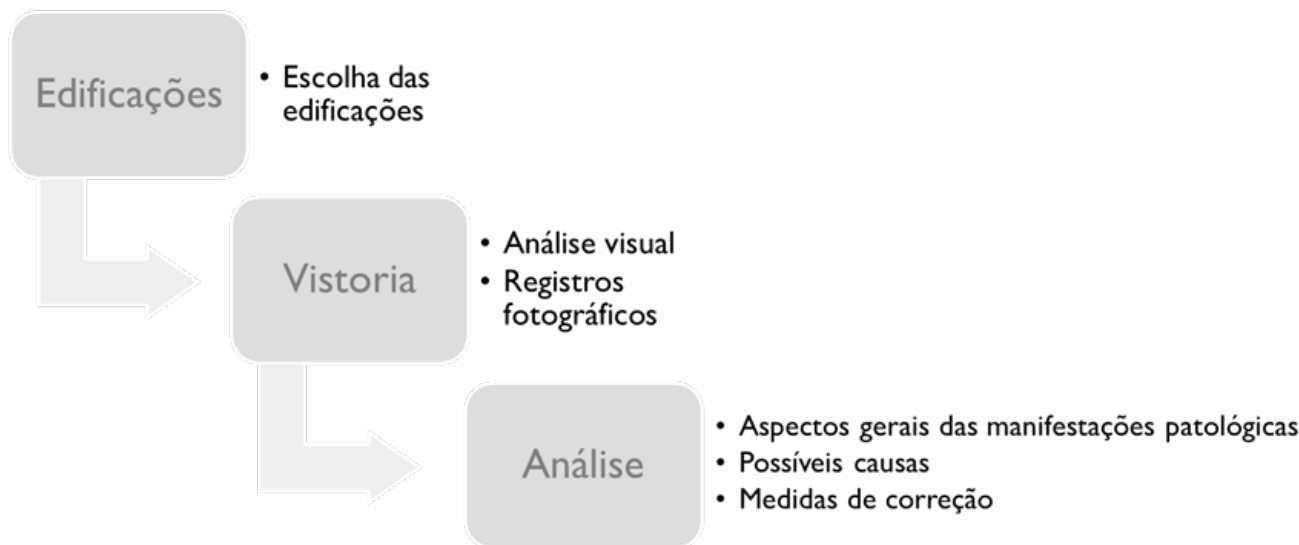

Figura 1: Fluxograma indicando as etapas desenvolvidas na metodologia 


\subsection{Escolha das edificações}

A escolha das edificações foi baseada nos seguintes critérios básicos: sistema estrutural utilizando aço como material e edificações com múltiplos pavimentos. Como critérios secundários, tem-se a idade da edificação e facilidade de acesso.

\subsection{Vistoria das edificações}

A vistoria das edificações consistiu em uma inspeção visual - e utilizando os cinco sentidos humanos - das manifestações patológicas encontradas, com observação dos aspectos das anomalias e registros fotográficos in loco. Foram consideradas manifestações patológicas situadas no próprio sistema estrutural e na interação da estrutura com outros elementos (como a alvenaria, por exemplo).

\subsection{Análise}

Após a realização da vistoria, procedeu-se à análise e estudo das manifestações patológicas detectadas, estabelecendo possíveis causas e medidas de correção. As causas prováveis foram definidas com base em informações constantes em outros trabalhos da literatura, presentes na bibliografia consultada.

Vale ressaltar que limitações quanto ao acesso das informações das edificações e instrumentos disponíveis para inspeção tornaram inviável a proposição de um diagnóstico e prognóstico preciso e bem definido. Além disso, o foco do trabalho não é a elaboração de um laudo técnico, e sim um artigo técnico-cientifico que contribua para o estado da arte do tema em questão

\section{RESULTADOS E DISCUSSÃO}

\subsection{Breve histórico da Universidade Federal de Viçosa e das edificações}

A Universidade Federal de Viçosa está localizada no estado de Minas Gerais, e foi fundada em 1926 sob o nome de Escola Superior de Agricultura e Veterinária (ESAV). Somente a partir de 1969 foi federalizada e recebeu o título de Universidade Federal de Viçosa. A instituição conta com três campi: Viçosa, Florestal e Rio Paranaíba.

O campus Viçosa (Figura 2) é o maior dentre os demais em termos de matrículas, atividades acadêmicas e área física, além de ser o mais antigo. Inicialmente, os cursos oferecidos pela instituição eram voltados à área agrária/rural. Com o passar dos anos, outras especialidades foram sendo desenvolvidas, e hoje a universidade possui 47 cursos de graduação dentro de quatro grandes centros: centro de ciências agrárias, exatas, humanas e biológicas. Este campus possui uma área construída de 431.001,94 m² (UFV, 2018), composta por edificações dos mais diversos tipos, incluindo cerca de 10 edifícios em estrutura metálica.

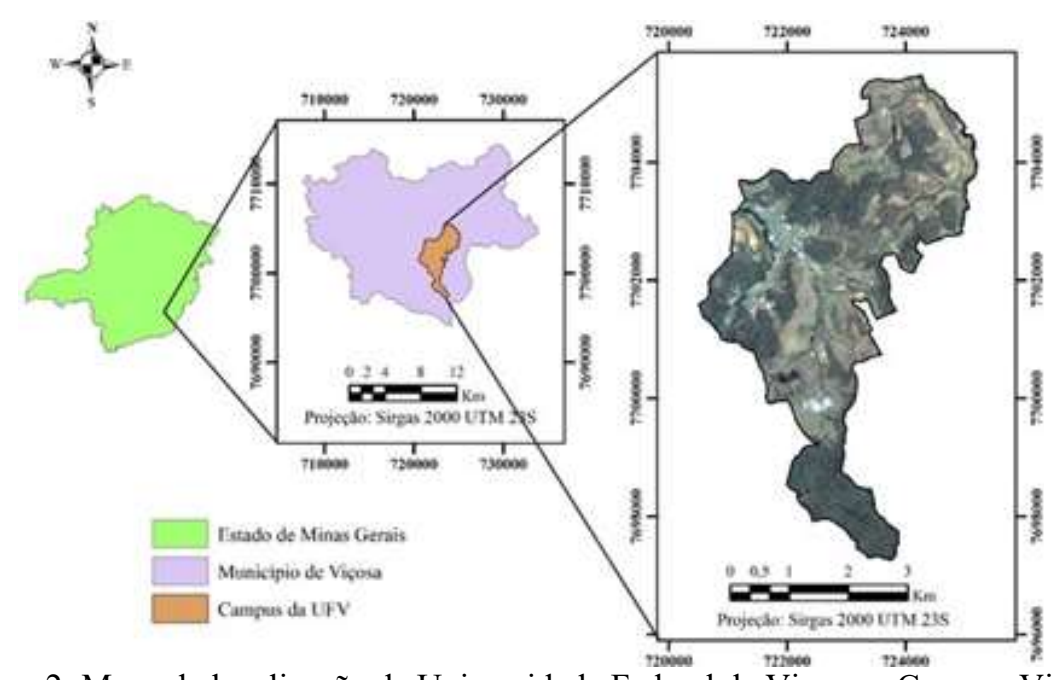

Figura 2: Mapa de localização da Universidade Federal de Viçosa - Campus Viçosa Fonte: Almeida et al. (2016) 
Quatro edificações em estrutura metálica foram escolhidas, que doravante serão denominadas como Edificação A, B, C e D. A seguir, é apresentada uma tabela contendo as informações principais acerca das edificações, como ano de inauguração, número de pavimentos e o caráter em termos de utilização (Tabela 1).

Tabela 1 - Informações gerais sobre as edificações vistoriadas no presente trabalho

\begin{tabular}{c|c|c|c|c}
\hline Edificação & $\begin{array}{c}\mathrm{N}^{\text {o de }} \\
\text { pavimentos }\end{array}$ & $\begin{array}{c}\text { Ano de } \\
\text { inauguração }\end{array}$ & Uso & $\begin{array}{c}\text { Classe de } \\
\text { agressividade } \\
\text { ambiental }\end{array}$ \\
\hline A & 4 & 1999 & $\begin{array}{c}\text { Salas de aula, laboratórios } \\
\text { e gabinetes de professores }\end{array}$ & CAA II \\
\hline B & 3 & 2013 & $\begin{array}{c}\text { Estúdio e cabines de } \\
\text { gravação, e salas de aula }\end{array}$ & CAA II \\
\hline C & 4 & 2018 & $\begin{array}{c}\text { Gabinetes de professores e } \\
\text { salas de aula }\end{array}$ & CAA II \\
\hline D & 3 & 2000 & Salas de aula e auditórios & CAA II \\
\hline
\end{tabular}

\subsection{Características das edificações e manifestações patológicas}

\subsubsection{Edificação A}

Os pilares e vigas da Edificação A são constituídos de aço estrutural ASTM A-36, e as lajes são do tipo steel-deck (ou laje mista). A alvenaria de vedação é feita de blocos cerâmicos, sendo interna em relação à estrutura nas fachadas principais; nas demais, a alvenaria se situa no plano da estrutura. Os principais perfis utilizados foram os perfis "W" $\mathrm{e}$ "U" laminados e soldados. As manifestações patológicas detectadas são mostradas na Tabela 2. Nas alvenarias, a principal anomalia detectada foi o desenvolvimento de fungos e musgos na parte externa, conforme visto na primeira imagem da Tabela 2.

Tabela 2 - Manifestações patológicas da Edificação A

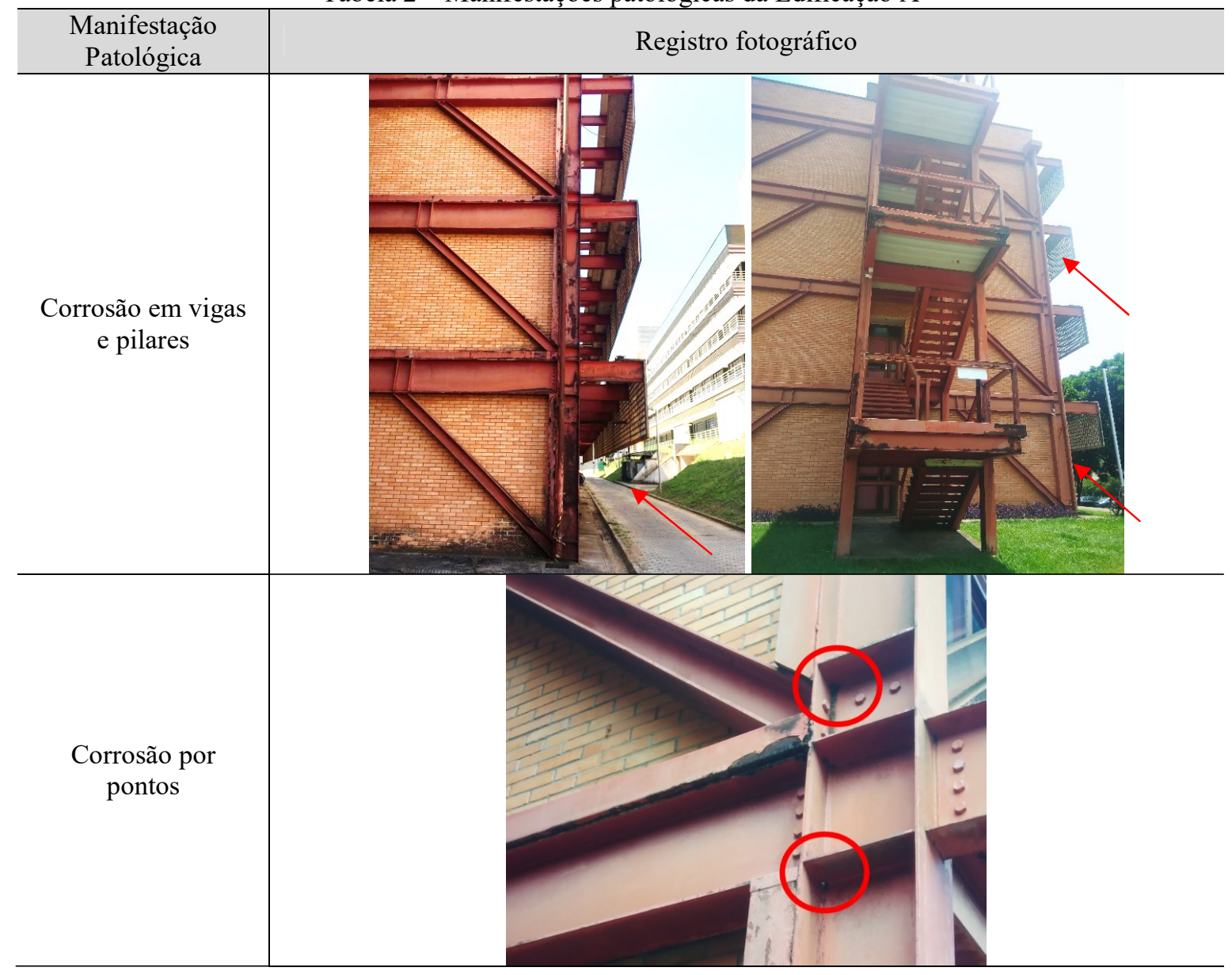




\subsubsection{Edificação B}

$\mathrm{Na}$ Edificação B, houve maior ocorrência de manifestações patológicas em perfis metálicos "W" e circulares. O aço estrutural utilizado foi o aço ASTM A-36, sendo os perfis W laminados. As lajes são constituídas de steel deck, e a alvenaria é externa à estrutura. As principais manifestações patológicas encontradas são mostradas na Tabela 3.

Tabela 3 - Manifestações patológicas da Edificação B

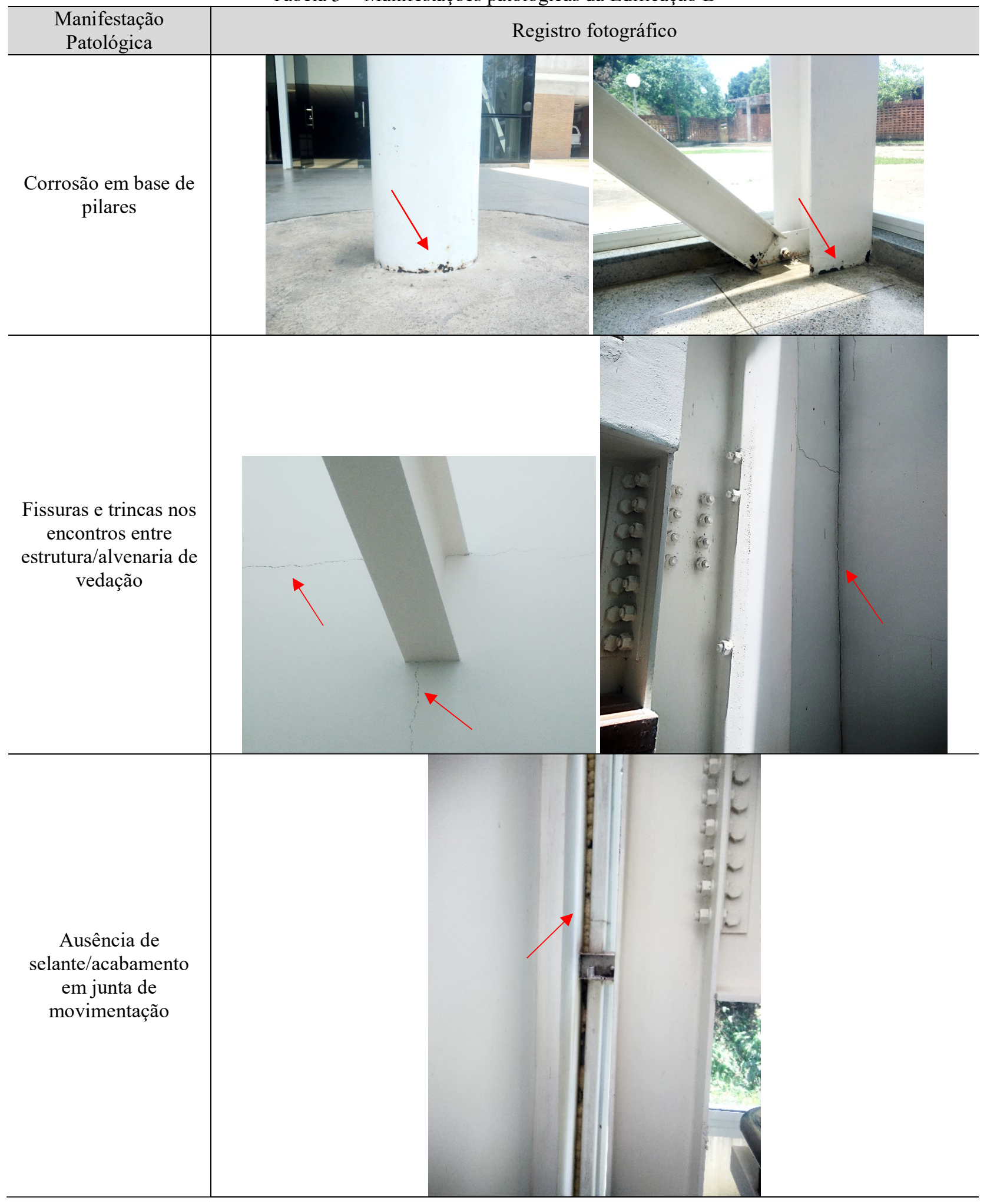




\subsubsection{Edificação C}

Na Edificação C, as vigas e o pilares internos são constituídos, majoritariamente, de perfis "W" laminados. Os pilares externos, por sua vez, possuem formato retangular, sendo compostos por um perfil W no centro, perfis cantoneira nos cantos e chapas metálicas parafusadas nas laterais. As lajes são feitas de steel deck e a alvenaria é feita de tijolos cerâmicos, interna à estrutura. As anomalias detectadas são mostradas na Tabela 4.

Tabela 4 - Manifestações patológicas da Edificação C

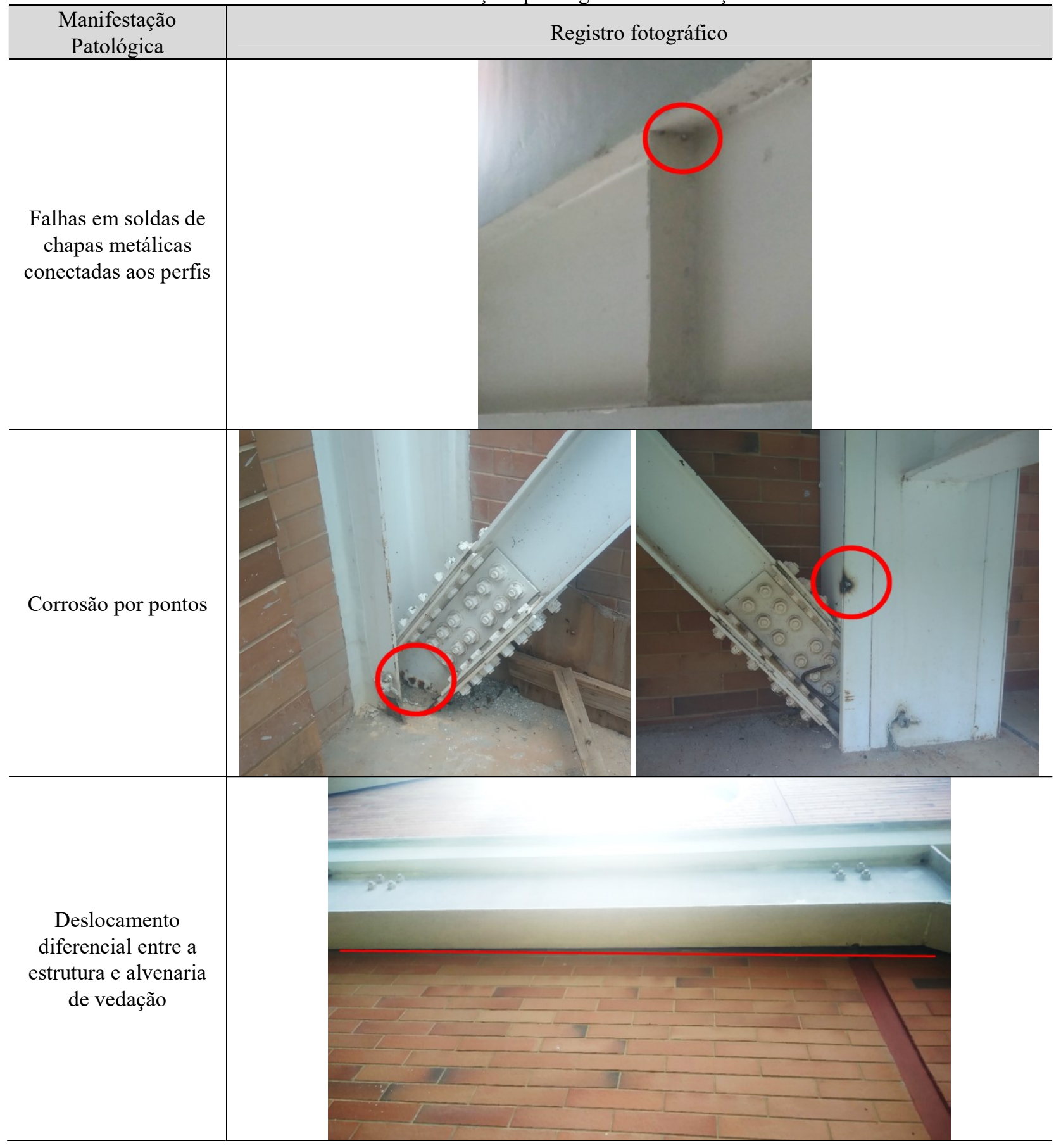

\subsubsection{Edificação D}

A estrutura da Edificação D é composta por vigas (treliçadas e de alma cheia) e pilares em perfis "W" soldados, "U" formados a frio e cantoneiras. A laje é feita em steel deck e a alvenaria de vedação externa está posicionada no plano da 
estrutura. $\mathrm{Na}$ entrada, tem-se uma cobertura treliçada com o emprego de perfis circulares, além dos já mencionados anteriormente. As manifestações patológicas são mostradas na Tabela 5.

Tabela 5 - Manifestações patológicas da Edificação D

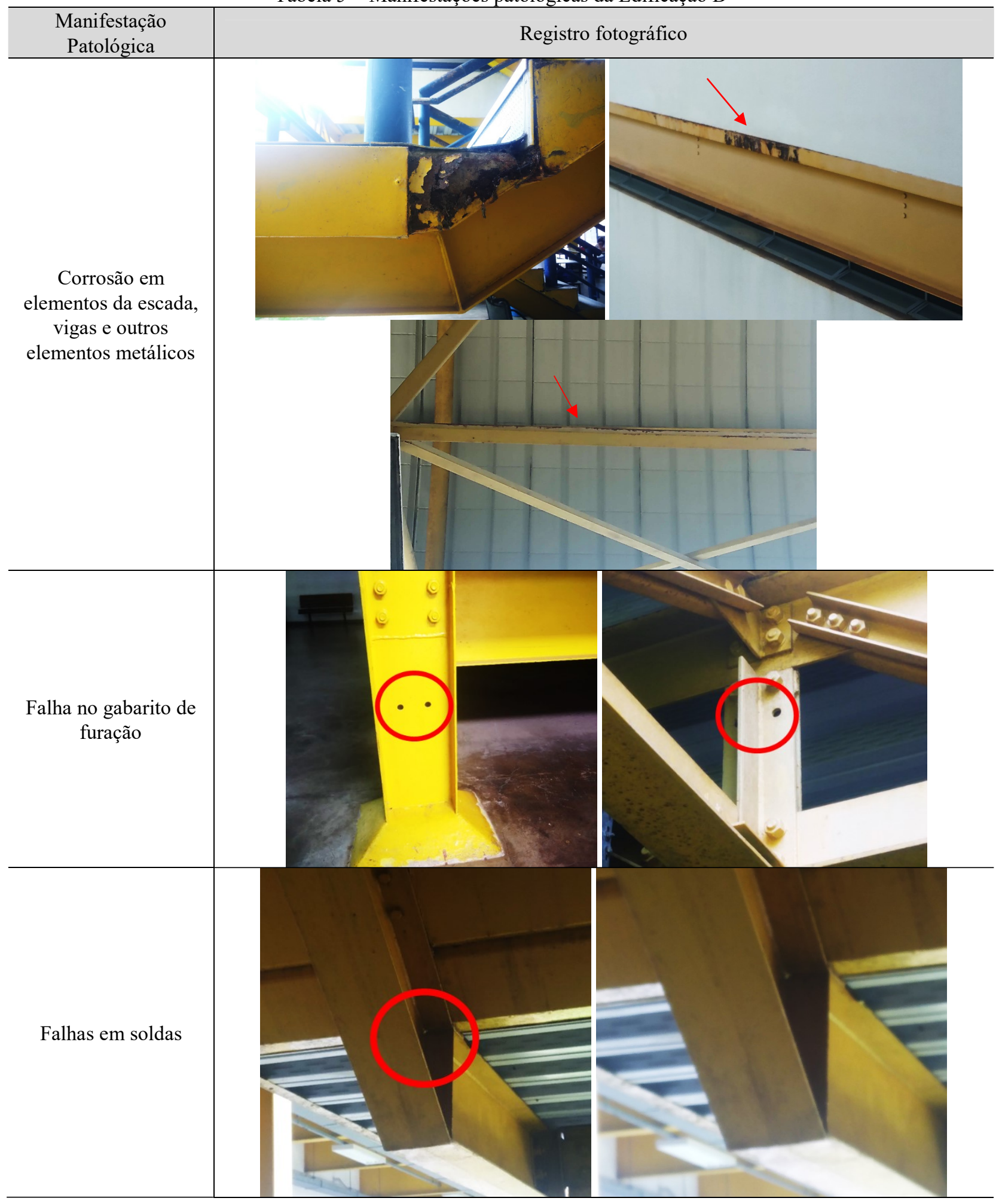

\subsection{Análise das manifestações patológicas encontradas}

Realizando uma análise geral das manifestações patológicas encontradas nas quatro edificações, observa-se que a anomalias encontradas foram: corrosão; fissuras e trincas no encontro estrutura/alvenaria; falha no gabarito de furação; 
falhas ou anomalias em soldas; ausência de selante ou acabamento em juntas de movimentação; e deslocamento diferencial entre a estrutura e painel de alvenaria. A partir das observações in loco, foram definidos os aspectos gerais de cada manifestação e possíveis causas, conforme mostrado na Tabela 6.

A classificação das aberturas em fissuras e trincas baseou-se no critério da ABNT NBR 15575-2:2013, sendo as aberturas de até $0,5 \mathrm{~mm}$ classificadas como fissuras, e igual ou superior a $0,6 \mathrm{~mm}$ classificadas como trincas.

Tabela 6 - Aspectos gerais e possíveis causas das manifestações patológicas

\begin{tabular}{|c|c|c|}
\hline $\begin{array}{c}\text { Manifestação } \\
\text { patológica }\end{array}$ & Aspectos gerais & Possíveis causas \\
\hline Corrosão & $\begin{array}{l}\text { - Destacamento da pintura; } \\
\text { - } \quad \text { Manchas avermelhadas; } \\
\text { - Redução da seção transversal do } \\
\text { elemento/perda de massa. }\end{array}$ & $\begin{array}{l}\text { - Ação de agentes ambientais externos (chuva, } \\
\text { umidade, etc); } \\
\text { - Proteção com pintura ineficiente ou } \\
\text { inadequada; } \\
\text { - } \quad \text { Preparação inadequada da superfície; } \\
\text { - Uso de materiais com má qualidade; } \\
\text { - } \quad \text { Falta de manutenção; } \\
\text { - } \quad \text { Ausência de detalhes construtivos ou detalhes } \\
\text { insuficientes. }\end{array}$ \\
\hline $\begin{array}{l}\text { Fissuras e trincas nos } \\
\text { encontros entre } \\
\text { estrutura e alvenaria }\end{array}$ & $\begin{array}{l}\text { - Trincas verticais e horizontais, } \\
\text { acompanhando os perfis; } \\
\text { - Fissuras no revestimento } \\
\text { argamassado da alvenaria. }\end{array}$ & $\begin{array}{l}\text { - Falta de detalhamento correto da ligação entre } \\
\text { - U alvenaria e a estrutura, ou falha na execução; } \\
\text { - Uso de materiais inadequados; } \\
\text { Variação de temperatura (movimentação } \\
\text { térmica). }\end{array}$ \\
\hline Furos em soldas & $\begin{array}{l}\text { - Pequenos furos em soldas de } \\
\text { ligação dos perfis; } \\
\text { - Não se observou aspecto de } \\
\text { corrosão. }\end{array}$ & $\begin{array}{l}\text { - } \quad \text { Execução de solda com má qualidade; } \\
\text { - Falta de inspeção e verificação das ligações } \\
\text { soldadas. }\end{array}$ \\
\hline $\begin{array}{l}\text { Falha no gabarito de } \\
\text { furação }\end{array}$ & $\begin{array}{l}\text { - Furos irregulares e sem a presença } \\
\text { de parafusos. }\end{array}$ & $\begin{array}{l}\text { - Erro de projeto ou falta de detalhamento } \\
\text { correto; } \\
\text { - Falha na execução dos furos. }\end{array}$ \\
\hline $\begin{array}{l}\text { Ausência de } \\
\text { selante/acabamento } \\
\text { em juntas de } \\
\text { movimentação } \\
\end{array}$ & $\begin{array}{l}\text { - Junta entre o pilar metálico e a } \\
\text { alvenaria com preenchimento } \\
\text { parcial e sem proteção com selante } \\
\text { ou outro acabamento. }\end{array}$ & $\begin{array}{l}\text { - Falta de detalhamento em projeto (ou } \\
\text { detalhamento incorreto); } \\
\text { - Erro de execução. }\end{array}$ \\
\hline $\begin{array}{l}\text { Deslocamento } \\
\text { diferencial entre a } \\
\text { viga estrutural e o } \\
\text { painel de alvenaria }\end{array}$ & $\begin{array}{l}\text { - Deslocamento } r \text { diferencial } \\
\text { perceptível, da olho nu, do painel } \\
\text { de alvenaria em relação à } \\
\text { estrutura. }\end{array}$ & $\begin{array}{l}\text { - } \quad \text { Execução de alvenaria desalinhada; } \\
\text { - Movimentação da estrutura ou da alvenaria } \\
\text { devido a agentes (forças) externos. }\end{array}$ \\
\hline
\end{tabular}

Analisando de modo mais detalhado as anomalias verificadas nas quatro edificações vistoriadas, observa-se que a manifestação mais ocorrente foi a corrosão. Isso porque, na maioria dos casos avaliados, os elementos estruturais em aço estão expostos ao ambiente, e consequentemente à ação de intempéries. A presença de umidade, incidência da água da chuva e temperaturas amenas (temperatura ambiente) são condições necessárias para a ocorrência deste tipo de degradação. A corrosão, além de provocar a perda de massa do material e alteração das suas características físicas e mecânicas, afeta ainda a estética da edificação. Na edificação A, a incidência de corrosão pode ser considerada generalizada, por abranger grande parte dos perfis externos. Nas edificações B e C, verificou-se esta anomalia apenas em alguns pontos isolados. $\mathrm{Na}$ edificação $\mathrm{D}$, a ocorrência foi inferior em comparação com a Edificação A, havendo corrosão mais intensa em peças externas e nos perfis das escadas.

A pintura dos perfis metálicos contribui para o aumento da resistência à corrosão dos mesmos; no entanto, se o procedimento de pintura é mal especificado ou mal executado, e os materiais utilizados não possuem qualidade adequada, esta medida de proteção se torna ineficaz. Além disso, mesmo que a pintura seja realizada de maneira correta, a sua degradação pode ocorrer com o passar dos anos, sendo necessária uma intervenção antes que os perfis sejam comprometidos. Isso indica a importância da existência de um plano de manutenção programada, para prevenção e/ou correção. 
A disposição dos perfis pode ainda contribuir para o acúmulo de água e poeira, acelerando o processo de corrosão. Em algumas das edificações vistoriadas, por exemplo, foram observadas chapas horizontais conectadas nas almas de pilares externos, o que favorece este acúmulo.

Uma atenção especial deve ser dada aos detalhes construtivos adotados, que podem contribuir para minimizar ou aumentar a ocorrência de corrosão na estrutura metálica. Na Edificação A, por exemplo, foram colocados brises de concreto na fachada frontal. No entanto, estes brises não impedem que a água da chuva incida e escorra sobre as vigas e pilares em aço. Além disso, nesta mesma edificação, algumas tubulações de água pluvial foram instaladas ao lado de pilares externos, promovendo maior contato da base destes pilares com a água líquida. No caso da Edificação D, mesmo os perfis posicionados sob a cobertura foram afetados por esta anomalia, o que pode estar associado ao fato destas coberturas não serem totalmente estanques à água da chuva.

Em relação à fissuração nos encontros entre estrutura e alvenaria, observou-se grande incidência na Edificação B. Uma possível causa é a definição de uma ligação que não permite a movimentação ou acomodação da alvenaria em relação à estrutura; com o deslocamento impedido, tensões são geradas, promovendo o surgimento das fissuras. Outra possibilidade é a má execução destas ligações, mesmo que o detalhamento tenha sido feito de maneira correta. Embora a variação da temperatura (devido à incidência solar) possa provocar a deformação térmica dos componentes, e consequentemente resultar na fissuração, foram detectadas fissuras também em elementos de alvenaria internos, que não sofrem incidência solar (Figura 3). Logo, nestes casos, a causa provável é justamente a acomodação entre alvenaria e estrutura.

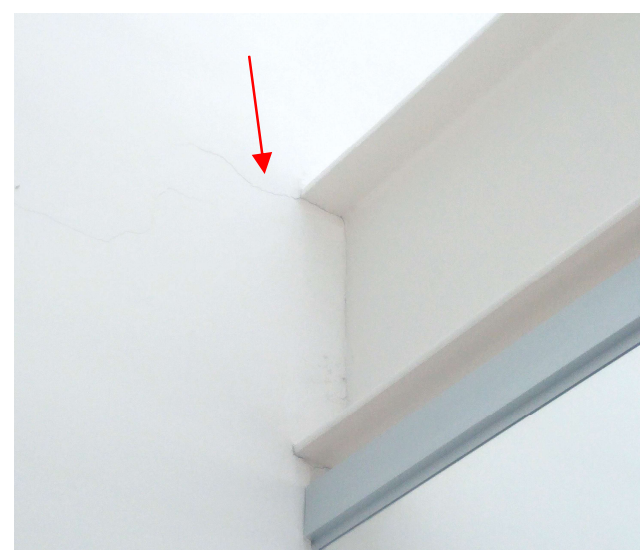

Figura 3: Fissura em encontro do perfil estrutural com a alvenaria interna

Detalhamentos corretos seriam aqueles que limitam as tensões atuantes a níveis que podem ser resistidos pelas paredes, principalmente nas interfaces alvenaria/estrutura. Duas opções seriam: a execução de juntas de controle que permitam a dissipação das tensões; ou reforços metálicos que sejam capazes de resistir às tensões nas regiões mais solicitadas. Uma prática comum é a utilização de telas metálicas soldadas, com fios de 1,65 mm, nos encontros alvenaria/pilar (Figura 4). Pode-se ainda executar uma ligação desvinculada deformável, na qual a alvenaria tem maior grau de liberdade em relação à estrutura (SILVA, 2003). Um exemplo de execução desta ligação é mostrado na Figura 5.

ISOMÉTRICO

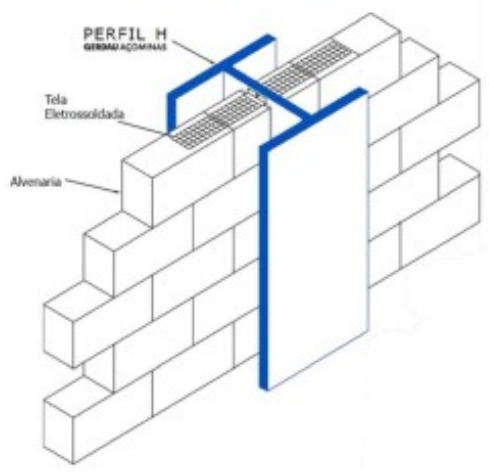

PLANTA

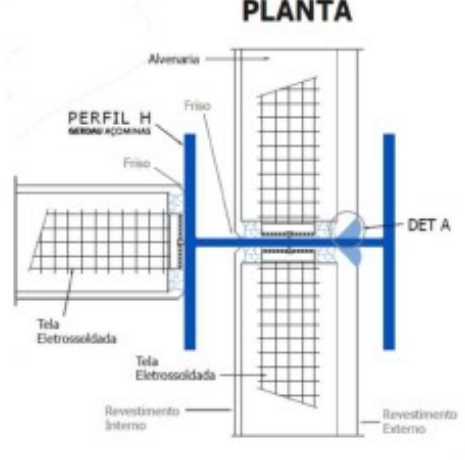

Figura 4: Aplicação de tela soldada em encontro alvenaria/pilar metálico Fonte: Coelho (2004) 


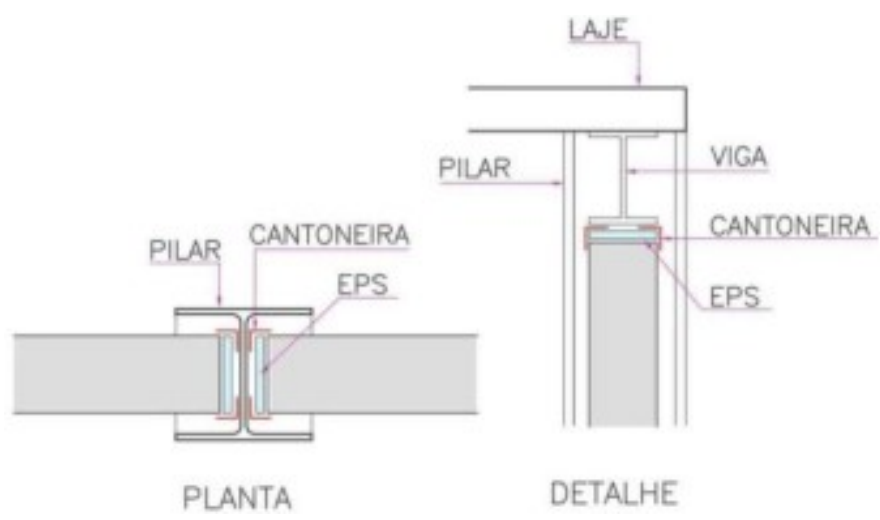

Figura 5: Exemplo de ligação desvinculada deformável

Fonte: Santos (2016).

Os furos em soldas de chapas metálicas foram observados nas edificações C e D. Como não foram verificados aspectos relacionados à corrosão, esta anomalia pode ter ocorrido em virtude da qualidade da solda, envolvendo má execução ou uso de materiais inadequados. Conforme mostrado nas imagens anteriores, os furos são de pequenas dimensões, não provocando danos graves às ligações ou elementos.

As falhas no gabarito de furação foram detectadas em vários elementos metálicos da Edificação D. Observou-se que foram feitos furos nos perfis e não houve a colocação de parafusos, indicando que os furos foram realizados em posições incorretas do elemento. Estes erros podem ter origem tanto no projeto, detalhamento dos perfis ou mesmo na execução, durante o processo de montagem. Em edificações mais recentes, como as edificações B e C, estas falhas não foram observadas, indicando uma possível melhora na execução deste sistema construtivo.

Uma falha encontrada apenas na Edificação B foi a ausência de selante e/ou acabamento na face interna de uma junta de movimentação. Notou-se que o material de preenchimento já havia sido parcialmente deteriorado, e a falta de fechamento da junto possibilitou a entrada de sujeira e agentes biológicos. Este problema pode ter ocorrido em virtude da falta de especificação, em projeto, deste acabamento ou uma má execução.

Por fim, tem-se o deslocamento diferencial verificado na Edificação C. Notou-se um desvio progressivo da alvenaria externa em relação à estrutura, na direção perpendicular ao plano vertical. Este desvio pode ter se originado ainda na fase de execução, com a elevação da alvenaria desalinhada, ou devido à ação de forças externas que provocaram o deslocamento da alvenaria ou da estrutura.

Diante das hipóteses levantadas como causas, foram sugeridas algumas medidas de correção para os problemas observados (Tabela 7). Vale ressaltar que a correção só pode ser aplicada após o diagnóstico correto do problema; desta forma, cada uma das anomalias supracitadas deve ser mais bem avaliada antes de se adotar uma intervenção. Além disso, para todas as edificações, recomenda-se que sejam realizadas visitas periódicas visando à observação e identificação de novas manifestações, bem como a realização de manutenções programadas - preventivas e corretivas.

Tabela 7 - Propostas de correção para as manifestações patológicas encontradas

\begin{tabular}{c|ll}
\hline Manifestação patológica & \multicolumn{1}{c}{ Medidas de correção } \\
\hline Corrosão & $\bullet \begin{array}{l}\text { Limpeza superficial com jato de areia (ou limpeza mecânica) e } \\
\text { repintura; } \\
\text { Para os casos mais graves, indica-se a realização de reforço ou } \\
\text { substituição dos perfis danificados; } \\
\text { • Manutenção periódica. }\end{array}$ \\
\hline $\begin{array}{c}\text { Fissuras nos encontros } \\
\text { entre estrutura e alvenaria }\end{array}$ & $\bullet \begin{array}{l}\text { Verificação da atividade das fissuras (ativas ou passivas); } \\
\text { Execução de juntas ou colocação de telas metálicas na junção } \\
\text { Estrutura/alvenaria. }\end{array}$ \\
\hline Falhas em soldas & $\bullet \quad$ Reparo do cordão de solda. \\
\hline Ausência de & $\bullet \quad \begin{array}{l}\text { Refazer o preenchimento e aplicar um selante ou outro } \\
\text { dispositivo de proteção da junta. }\end{array}$ \\
\hline juntas de movimentação & &
\end{tabular}


No caso das falhas no gabarito de furação, não é necessário realizar alguma intervenção caso o furo não comprometa o desempenho mecânico ou a funcionalidade da peça estrutural. No entanto, se isto ocorrer, sugere-se a substituição do elemento ou a colocação de um elemento de reforço. Esta tomada de decisão pressupõe uma inspeção mais detalhada e análises mais complexas.

Em relação ao deslocamento diferencial entre a viga estrutural e o painel de alvenaria, o mesmo se aplica; não há a necessidade de correção ou reparo caso a segurança e funcionalidade da edificação não seja afetada. No entanto, recomenda-se uma vistoria periódica no intuito de verificar se o deslocamento está progredindo ao longo do tempo, e se não há outros danos na alvenaria e na estrutura do local.

\subsection{Ações para melhoria da qualidade das edificações em estrutura metálica}

Diante das manifestações patológicas observadas nos edifícios institucionais visitados, algumas ações podem ser indicadas para a melhoria da qualidade de edificações em estruturas metálicas. Como boa parte das possíveis causas está relacionada aos projetos e detalhamentos, é importante que haja uma equipe de profissionais especializada na elaboração e compatibilização de projetos para este tipo de sistema construtivo. É importante ressaltar que, se a estrutura for metálica, sua concepção deve ser feita para esta realidade, de modo a aproveitar melhor sua potencialidade. Ou seja, não é conveniente projetar uma estrutura em concreto armado, por exemplo, e adaptá-la para ser feita em aço, uma vez que cada sistema construtivo tem suas particularidades.

A compatibilização entre os projetos arquitetônico, estrutural, e de instalações (elétricas, hidrossanitárias, etc.) é muito importante no contexto das estruturas metálicas, por se tratar de um sistema racionalizado. Assim, deve-se dar atenção à interação entre os diversos elementos construtivos e prever os possíveis efeitos negativos que podem surgir. Os detalhes construtivos presentes nos projetos devem ser claros e bem detalhados, com todas as especificações necessárias, sem que haja dúvidas no momento da execução. Devem ser prescritos materiais de qualidade, e adequados para a finalidade proposta. Além disso, é necessário que os projetos contemplem as normas vigentes, atendendo a todas as especificações e limites estabelecidos, e prevendo os efeitos que podem ocorrer na estrutura de acordo com a utilização prevista.

Outro ponto importante é a necessidade de mão de obra qualificada para a execução e montagem dos elementos estruturais, e que entenda o conceito de racionalização inerente ao sistema construtivo em aço. Muitas das atividades devem ser executadas de maneira precisa e requerem mais habilidade. Os processos - como preparação da superfície dos perfis metálicos, limpeza e pintura - devem ser realizados de maneira correta, e com materiais adequados. É imprescindível a presença de um engenheiro civil nos processos executivos da edificação, evitando que sejam realizados procedimentos errôneos.

Por fim, é nítida a necessidade da existência de um programa de manutenção preventiva/corretiva para cada edificação. Dessa forma, muitas manifestações patológicas podem deixar de ocorrer ou serem detectadas no início, quando os custos de manutenção são menores em relação à uma intervenção a longo prazo. A corrosão, por exemplo, poderia ser minimizada se a limpeza e repintura dos perfis fosse periódica, evitando a necessidade de reforço ou troca de elementos no futuro. Se a manutenção é programada, a instituição pode se planejar (a um prazo maior) e alocar os recursos necessários para a realização das atividades de manutenção.

\section{CONCLUSÃO}

As principais conclusões obtidas após a realização do presente trabalho foram:

- A manifestação patológica mais ocorrente nas edificações vistoriadas foi a corrosão, que se apresentou em diferentes tipos e graus.

- Foram propostas algumas formas de correção específicas para as patologias observadas, e ações gerais para a melhoria da qualidade das edificações em estrutura metálica, incluindo a contratação de equipes e profissionais qualificados para manutenção corretiva de estruturas de aço e a adoção de um plano de manutenções programadas, elaborado com base em um estudo mais aprofundado.

- Este trabalho resultou em um levantamento de informações acerca de edificações institucionais da UFV, que pode nortear futuras manutenções e/ou intervenções nas estruturas de aço e contribuir para a literatura técnica relacionada ao assunto. 


\section{REFERÊNCIAS}

ALMEIRA, L. T. et al. Locação de corredores ecológicos e área de preservação permantente na Universidade Federal de Viçosa. Nativa, v. 4, n. 6, p. 412-418, nov./dez. 2016.

ASSOCIAÇÃO BRASILEIRA DE NORMAS TÉCNICAS. NBR 15575: Edificações habitacionais - Desempenho Parte 2: Requisitos para os sistemasestruturais. Rio de Janeiro, 2013.

CASTRO, E. M. C. Patologia dos edifícios em estrutura metálica. 202f. Dissertação (Mestrado em Engenharia Civil). Ouro Preto: Universidade Federal de Ouro Preto, Ouro Preto, 1999.

COELHO, R. de A. Interface entre perfis estruturais e laminados e sistemas complementares. 3. ed. São Paulo: Gerdau-Açominas, 2004. 63p. (Coletânea do uso do aço, v.1).

CORTEZ, L. A. R. et al. Uso das estruturas de aço no Brasil. Cadernos de Graduação, Maceió, v. 4, n. 2, p. 217-228, nov. 2017.

MARSIA, N. T.; SARTORI, A. L. Identification and analysis of pathologies in bridges of urban and rural roads. Revista Ingeniería de Construcción, v. 26, n. 1, p. 5-24, abr. 2011.

SACCHI, C. C.; SOUZA, A. S. C. Manifestações patológicas e controle de qualidade na montagem e fabricação de estruturas metálicas. Revista Eletrônica de Engenharia Civil, v. 13, n. 1, p. 20-34, 2016.

SANTOS, M. A. Recomendações para projeto e detalhamento de juntas e interfaces utilizadas em sistemas de vedação vertical em alvenaria para estruturas de aço. 152f. Dissertação (Mestrado em Engenharia Civil). Viçosa: Universidade Federal de Viçosa, Viçosa, 2016.

SANTOS, B. A.; FIORITI, C. F.; TSUTSUMOTO, N. Y. Investigação de manifestações patológicas nas estruturas de aço do Parque do povo. Anais... CONSTRUMETAL 2016. São Paulo: ABCEM, 2016.

SANTOS, T. S.; TSUTSUMOTO, N. Y.; FIORITI, C. F. Manifestações patológicas em edificações com estruturas de aço em Presidente Prudente. Anais... CONSTRUMETAL 2014. São Paulo: ABCEM, 2014.

SILVA, M. M. A. Diretrizes para o projeto de alvenarias de vedação. 274f. Dissrtação (Mestrado em Engenharia Civil). São Paulo: Universidade de São Paulo, São Paulo, 2003.

SOUZA, V. C. M.; RIPPER, T. Patologia, recuperação e reforço de estruturas de concreto. São Paulo: Pini, 1998. 